\title{
Armand Jean du Plessis, cardinal duc de Richelieu, Euvres théologiques. Tome 1. Traité de la perfection du chrétien
}

Texte établi et introduit par Stéphane-Marie Morgain et Françoise Hildesheimer, annoté par Stéphane-Marie Morgain, Paris, Honoré Champion, 2002, 500 p. (bibliogr., index).

Daniel-Odon Hurel

\section{(2) OpenEdition Journals}

Édition électronique

URL : http://journals.openedition.org/assr/1450

DOI : 10.4000/assr.1450

ISSN : $1777-5825$

Éditeur

Éditions de l'EHESS

Édition imprimée

Date de publication : 1 avril 2003

Pagination : 59-157

ISBN : 2-222-96732-5

ISSN : 0335-5985

Référence électronique

Daniel-Odon Hurel, « Armand Jean du Plessis, cardinal duc de Richelieu, Euvres théologiques. Tome 1. Traité de la perfection du chrétien », Archives de sciences sociales des religions [En ligne], 122 | avril - juin 2003, document 122.89, mis en ligne le 10 novembre 2005, consulté le 24 septembre 2020. URL : http://journals.openedition.org/assr/1450 ; DOI : https://doi.org/10.4000/assr.1450 
PLESSIS (Armand Jean du), Cardinal duc de Richelieu.

Euvres théologiques. Tome 1. Traité de la perfection du chrétien. (texte établi et introduit par Stéphane-Marie Morgain et Françoise Hildesheimer, annoté par Stéphane-Marie Morgain), Paris, Honoré Champion, 2002, 500 p. (bibliogr., index).

La réédition annotée de cet ouvrage posthume de Richelieu (publié en 1647) bien moins connu que son Instruction du chrétien mais rédigé au cœur de sa vie politique, entre 1636 et 1639 , complète s'il était encore nécessaire notre connaissance d'un Richelieu qui demeure, même au sommet de son activité politique, un théologien et un pasteur. L'introduction analyse les modalités de l'écriture de l'ouvrage (mettant en scène le cardinal luimême mais aussi plusieurs ecclésiastiques de son entourage). L'ouvrage se veut pédagogique, rationnel et simple. Il se situe dans un fort courant d'ouvrages consacrés à la perfection, émanant en particulier des milieux jésuites et capucins. Cependant, quelques influences majeures se dégagent (celle de Benoît de Canfield et de François de Sales) aboutissant aussi à quelques énoncés significatifs tels que la supériorité de l'oraison mentale sur l'oraison vocale, le primat de l'action sur la contemplation ou la nécessité d'adapter la dévotion à sa condition sociale. Sur le plan essentiel de la pratique sacramentelle (confession et communion), Richelieu se montre très favorable à l'équilibre pastoral et théologique des jésuites en matière de confession et de fréquente communion. Enfin, il n'oublie pas la controverse et s'aide pour cela de l'actualité des publications patristiques. Ouvrage d'actualité (mise en garde contre les «illuminés » dans les années 1635) s'adressant à un public large, Richelieu dénonce les dangers des tendances mystiques d'où cette insistance sur la vie active et la volonté, en une vingtaine de conseils, de définir une pratique spirituelle et dévotionnelle raisonnable.

Les choix en matière d'édition suggèrent quelques remarques. Puisque l'ouvrage a été déjà édité en 1647, et que dans la présente édition, l'orthographe a été modernisée tout comme la ponctuation, il n'aurait peut-être pas été inutile d'insérer dans le texte la pagination de l'édition originale, de manière à faciliter d'éventuelles comparaisons. D'autre part, lorsque Richelieu évoque l'extase mystique, il ne donne aucun exemple précis alors que l'annotateur renvoie lui, exclusivement ou presque, à Thérèse d'Avila. Cette lecture induite et par ailleurs justifiée est-elle la seule? La comparaison faite assez régulièrement dans l'annotation avec saint François de Sales laisse

entendre que non. L'édition est heureusement complétée par deux index, thématique et scripturaire.

Daniel-Odon Hurel.

\subsection{0}

Religions, droit et sociétés dans l'Europe communautaire. Actes du XIII ${ }^{\mathrm{e}}$ colloque de l'Institut de Droit et d'Histoire Religieux (IDHR), Aix-en-Provence 19-20 mai 1999, Presses universitaires d'Aix-Marseille, 2000, 294 p. (cf. Arch. supra, pp. 31-37).

RICHET (Isabelle).

La Religion aux États-Unis. Paris, PUF, 2001, 124 p. (bibliogr.) (coll. "Que sais-je ? »).

Proposer, dans un format aussi réduit que celui d'un «Que sais-je ? », une présentation raisonnée du fait religieux américain, s'agissant d'un pays qui compte des dizaines de confessions et des centaines de dénominations - mais pas d'Église nationale - constitue, note I.R., un véritable défi. Disons d'emblée que l'auteure, qui « vise à éclairer le lien étroit entre les forces religieuses et l'expérience américaine ellemême dont elles ont épousé et parfois piloté toutes les évolutions ", a magnifiquement relevé ce défi. À partir de trois notions-clés pluralisme, individualisme, nationalisme - I.R. dessine une configuration inséparablement religieuse, politique et culturelle à l'intérieur de laquelle elle ressaisit de façon synthétique les éléments descriptifs et historiques indispensables à la compréhension des logiques de la scène religieuse américaine. Qu'il s'agisse de la dynamique des réveils ou des connexions complexes de la communalisation religieuse américaine et du fait migratoire, de l'inscription des différents styles religieux américains dans la culture moderne de l'individu ou des sources historiques du messianisme américain, ce petit volume offre, dans une forme aussi concise qu'incisive, les éléments fondamentaux d'une analyse globale de la modernité religieuse américaine, toujours servie par une documentation précise. Une performance.

Danièle Hervieu-Léger. 